\title{
A KINETIC APPROACH TO DESCRIBE THE TIME EVOLUTION OF RED WINE AS A FUNCTION OF PACKAGING AND STORAGE CONDITIONS
}

\author{
F. Venturi ${ }^{\mathrm{a}, \mathrm{b}}$, C. Sanmartin ${ }^{\mathrm{a}, \mathrm{b}}$, I. TAglieri ${ }^{\mathrm{a}}$, Y. XiaOguo ${ }^{\mathrm{a}, \mathrm{c}}$, G. Andrich ${ }^{\mathrm{a}, \mathrm{b}}$ and A. Zinnal ${ }^{\mathrm{a}, \mathrm{b} *}$ \\ ${ }^{a}$ Department of Agriculture, Food and Environment, University of Pisa, Via del Borghetto 80, 56124, Pisa. Italy \\ 'Interdepartmental Research Center "Nutraceuticals and Food for Health", University of Pisa, \\ Via del Borghetto 80, 56124, Pisa. Italy \\ ${ }^{c}$ Zhejiang Provincial Key Laboratory of Health Risk Factors for Seafood, College of Food and Pharmacy, \\ Zhejiang Ocean University, China
}

(Received: 30 August 2016; accepted: 11 November 2016)

With the aim to determine the influence of packaging in preserving the quality of wine, in this research project the chemical and sensorial evolution of a red wine stored in different packaging materials (glass bottles vs multilayer Tetrabriks ${ }^{\circledR}$ ) has been evaluated over a period of 12 months. Furthermore, two different temperature levels (4 and $20^{\circ} \mathrm{C}$ ) for each packaging solution were maintained throughout the storage period.

The results show how the characteristics of packaging could deeply affect wine quality as a function of the storage conditions used, and suggest that with their rational optimization the quality of red wine during storage can be kept and its shelf life extended. In this context, the kinetic characterization of the time evolution of some chemical compounds that can be assumed as indexes of wine oxidation rate could enhance the consumer's enjoyment during tasting.

Under the adopted experimental conditions, the rate of wine aging was higher when the storage temperature increased. Furthermore, after 12 months of storage at room temperature, the glass bottles generally better preserved red wine from oxidation than multilayer Tetrabriks ${ }^{\circledR}$.

Keywords: kinetic model, $\mathrm{TSO}_{2}$ kinetic evolution, TAnt kinetic evolution, packaging, sensorial characterization, red wine aging, red wine storage

Nowadays, glass containers are still usually preferred for bottling wine (GHIDossi et al., 2012; WANI et al., 2014; VAN OOIJEN et al., 2016) being the only material with a high impermeability to gases and vapours, stability over time, transparency, and it is readily recyclable (MENTANA et al., 2009). Nevertheless, as a consequence of some objective limitations for the extensive use of glass containers in food industry (i.e. heavy weight, fragility to internal pressure, impact, and thermal shock, etc.) (WANI et al., 2014), in recent years there is growing worldwide demand for alternative solutions to glass also for bottling wine (Van OoIJen et al., 2016 and ref. within). Therefore, among all the possible packaging materials, it has been possible to observe an expansive utilization of polymeric materials for wine packaging, including PET bottles, multilayer Tetrabriks ${ }^{\circledR}$, and bag-in-box (BiB) type containers (RoBERTSOn, 2012; Revi et al., 2014; VANDERROost et al., 2014). In this context, the packaging options alternative to conventional glass containers are often marketed as inexpensive, practical to use, and "eco-friendly," particularly in relation to their contributions to waste prevention (Ghidossi et al., 2012; ClEARY, 2013).

\footnotetext{
* To whom correspondence should be addressed. Phone:+39-50-2216632; e-mail: angela.zinnai@unipi.it
} 
With the aim to determine the influence of packaging in preserving the quality of wine, in this research project both chemical and sensorial evolution of a not structured red wine stored in different packaging materials (glass bottles vs multilayer Tetrabriks ${ }^{\circledR}$ ) has been evaluated over a period of 12 months.

As it is well known, temperature influences the oxygen permeability of thermoplastic polymers (DomBre et al., 2015 and ref. within). As oxygen is one of the main factors affecting wine evolution as well as its deterioration (KwIATKOwSKI et al., 2007; GHIDOSSI et al., 2012; Dombre et al., 2015 and ref. within), two different temperature levels (4 and $20{ }^{\circ} \mathrm{C}$ ) for each packaging solution were maintained throughout the storage period (12 months).

As glass is characterized by a high impermeability to gases and vapours (MENTANA et al., 2009), when wine is stored in a glass bottle, the barrier against the external atmosphere is provided by the closure. Additionally, according to the results reported in a previous paper (Venturi et al., 2016a), the wine stored in glass bottle closed with crown cap showed the lowest degradation rate if compared with the same wine stored in the same operating conditions in glass bottles closed with different kinds of closures (natural cork, screw cap, polymeric material). In order to highlight the real influence of the different packaging materials (glass vs multilayer Tetrabriks ${ }^{\circledR}$ ) on the evolution of the stored wine, the glass bottles were closed with crown cap, with the purpose of avoiding the influence of closure on the wine evolution.

\section{Materials and methods}

\subsection{Experimental protocol adopted}

The red wine $\left(\mathrm{pH}=3.62 \pm 0.01 ;\right.$ alcohol $(\% \mathrm{v} / \mathrm{v})=12.50 \pm 0.01$; titratable acidity $=4.82 \pm 0.20 \mathrm{~g}^{-1}$ as tartaric acid; net volatile acidity $=0.55 \pm 0.02 \mathrm{~g} \mathrm{l}^{-1}$ as acetic acid; total phenols $=3.87 \pm 0.01$ $\mathrm{g}^{-1}$ as catechins; not flavonoid phenols $=0.440 \pm 0.03$ as gallic acid; total anthocyanins $=$ $0.470 \pm 0.006 \mathrm{~g} \mathrm{l}^{-1}$ as malvin; proanthocyanidins $=1.097 \pm 0.01 \mathrm{~g} \mathrm{l}^{-1}$ as catechins; total $\mathrm{SO}_{2}=0.100 \pm 0.007 \mathrm{~g} \mathrm{l}^{-1}$ ) was packed in different packaging materials (glass bottles, $\mathrm{V}=1 \mathrm{l}$; Tetrabriks ${ }^{\circledR}, V=1$ l) at the same time in a commercial winery bottling line using a fully automated bottling/filling station.

Packed wine was shipped by air-conditioned truck $\left(\mathrm{T}=20 \pm 1^{\circ} \mathrm{C}\right)$ from the bottling/filling facility located at Castellina Marittima (PI) to the Food Technology Laboratory of the DAFE (University of Pisa) 1 day after bottling/packaging. Sampling of wine was carried out at 3 days, 3, 6, 9, and 12 months of storage. During the whole observation period, all samples were stored in a controlled temperature cabinet at two different temperature levels: $4 \pm 1{ }^{\circ} \mathrm{C}$ and $20 \pm 1{ }^{\circ} \mathrm{C}$. Table 1.

The specific experimental conditions adopted in each experimental run are reported in

\begin{tabular}{|c|c|}
\hline Run & Storage conditions \\
\hline 1 & Glass $20^{\circ} \mathrm{C}$ \\
\hline 2 & Glass $4^{\circ} \mathrm{C}$ \\
\hline 3 & TB $20^{\circ} \mathrm{C}$ \\
\hline 4 & $\mathrm{~TB} 4{ }^{\circ} \mathrm{C}$ \\
\hline
\end{tabular}




\subsection{Chemical evolution}

All chemical determinations useful for the characterization of starting wine were run at the laboratory of Food Technology of DAFE (University of Pisa) according to official methods proposed by International Organization of Vine and Wine (OIV) and described in Compendium of International Methods of Wine and Must Analysis (OIV, 2014): OIV-MA-AS313-15 (pH); OIV-MA-As313-01 (Total acidity); OIV-MA-AS312-01A (Alcoholic strength by volume); OIV-MA-AS313-01 (Net volatile acidity). The determination of the main phenolic compounds was run according to the official methods proposed by AMERINE and OUGH (1988).

The methods utilized for the determination of $\mathrm{TSO}_{2}$ and TAnt during wine storage are described in detail below.

1.2.1. Total $\mathrm{SO}_{2}\left(\mathrm{TSO}_{2}\right)$. Time evolution of total $\mathrm{SO}_{2}\left(\mathrm{TSO}_{2}\right)$ concentration was determined at the laboratory of Food Technology of DAFE (University of Pisa) by the Ripper titrimetric method (ZoECKLEIN et al., 1999).

This method is based on the redox reaction, where sulphur dioxide, in the form of bisulphite ion, reacts with iodine as follows:

$$
\mathrm{HSO}_{3}{ }^{-}+\mathrm{I}_{3}{ }^{-}+\mathrm{H}_{2} \mathrm{O} \rightarrow \mathrm{SO}_{4}{ }^{-}+3 \mathrm{H}^{+}+3 \mathrm{I}^{-}
$$

Unreacted iodine forms a blue complex with starch indicator to signify the endpoint. The addition of sodium bicarbonate prior to commencing the titration creates an inert blanket of carbon dioxide gas to prevent interference caused by oxygen in air. Red wines may require decolourising with activated carbon prior to performing the titration in order for the endpoint colour change to be observed. When determining total sulphur dioxide, the sample is pretreated with sodium hydroxide solution to adjust the $\mathrm{pH}$. This causes chemically bound forms of sulphur dioxide to be released in the solution as free sulphur dioxide. It is essential to titrate to an endpoint, where the blue colour persists for 30 seconds to ensure that all forms of sulphur dioxide in solution have reacted.

1.2.2. Total Anthocyanins (TAnt). As described in a previous paper (ZINNAI et al., 2011a), the time evolution of TAnt concentration was determined at the laboratory of Food Technology of DAFE (University of Pisa) by measuring the absorbance at $540 \mathrm{~nm}$ after dilution of the sample with a solution composed by ethanol/water $/ \mathrm{HCl}=70 / 30 / 1$. The concentration of anthocyanins was calculated (as $\mathrm{g}^{-1}$ of malvidin equivalent) using the equation:

$$
[\text { TAnt }]=\frac{A b s_{(540 \mathrm{~nm})}}{\varepsilon} \times \text { dil. } \times 332
$$

where $\operatorname{Abs}_{(540 \mathrm{~nm})}=$ Absorbance at $\lambda=540 \mathrm{~nm} ; \varepsilon=$ molar attenuation coefficient, according to Beer's law; dil.=dilution of wine sample, generally ranging from 1:20 to 1:50 (v/v); $332=$ molecular weight of malvidin.

1.2.3. Mathematical model. As reported in previous papers (ZINNAI et al., 2011b; VENTURI et al., 2015), the identification of the best values to be assigned to the model parameters was carried out by the specific statistical program BURENL (Buzzi FerRARIs \& MANCA, 1996). 
This program identifies, in a space of $\mathrm{j}$-dimensions (where $\mathrm{j}$ represents the number of equation parameters), the minimum value of $\mathrm{F}$ function, which is obtained from the sum of the squares of differences occurring between calculated and experimental values:

$$
\mathrm{F}=\sum_{\mathrm{i}=1}^{N}\left(R_{\text {calc.,i }}^{*}-R_{\text {exper.,i }}^{*}\right)^{2}
$$

where $\mathrm{i}=\mathrm{i}$ calculated/experimental value, and $\mathrm{N}=$ total number of experimental values.

\subsection{Sensorial evaluation}

The sensorial profiles of wine as a function of the storage packaging were evaluated by a trained panel from the "expert panel" of the Department of Agriculture, Food and Environment (DAFE) of University of Pisa; all assessors had previous experience in sensory descriptive analysis, mainly in wine evaluation. According to the DAFE internal procedure for assessor selection and training (VENTURI et al., 2013; Venturi et al., 2014; VenTURI et al., 2016b), based on a normalized technical procedure reported in the literature (PÉREZ ElORTONDO et al., 2007), expert assessors must repeat and pass re-qualification tests at least once a year to demonstrate that they are satisfactorily still capable of evaluating the samples.

The assessors were provided with a specifically developed sensorial sheet consisting of a not structured, parametric, descriptive wine scoring chart. Tasting was carried out in the morning, in a well-ventilated quiet room, and in a relaxed atmosphere. Before evaluation, samples were left for $2 \mathrm{~h}$ at room temperature in order to serve all samples at the same temperature. The wine was then presented to assessors at the same time. Regardless of the packaging conditions, a randomized serving order was proposed. All assessments were repeated in duplicate in two different days by the same group of panellists.

\subsection{Statistical analysis}

(i) Chemical characterization: in order to evaluate the statistical significance of the experimental data, from the same bottle all measurements were repeated in triplicate.

The reliability of data sets (4 treatments for three repeated analysis) was evaluated by One Way Completely Randomized ANOVA (CoStat, Cohort 6 software). Comparisons among means were performed by Bartlett's X2 corrected test $(\mathrm{P}<0.05)$. Tukey's HSD multiple mean comparison test $(\mathrm{P}<0.05)$ was used to state the differences among variables.

(ii) Sensorial analysis: for each tasting session, the reliability of the assessments was evaluated by 2-Way Completely Randomized ANOVA (software R, version 3.3.1) by Bartlett's test $(\mathrm{P}<10,51 \%)$, with Product (packaging and storage conditions adopted) and Panellist as main factor. Tukey's HSD multiple mean comparison test $(\mathrm{P}<10,51 \%)$ was used to state the differences among variables.

(iii) Matrix of correlation: Pearson's correlation coefficient test was also carried out to measure the strength of the correlation among $\mathrm{TSO}_{2}$ and TAnt degradation kinetic constant $\left(\mathrm{k}_{\mathrm{TSO}_{2}} ; \mathrm{k}_{\mathrm{TAnt}}\right)$ and the main wine attributes that are generally associated with oxidation. Generally, a coefficient of about \pm 0.7 or more is regarded as indicating fairly strong correlation, and in the region of \pm 0.9 , it indicates very strong correlation. In the region of \pm 0.5 the correlation is moderate, and in the range -0.3 to +0.3 , it is weak (LEIGHTON et al., 2010). 


\section{Results and discussion}

\subsection{Chemical evolution of stored wine}

2.1.1 Kinetics of $\mathrm{TSO}_{2}$ and TAnt degradation. As $\mathrm{SO}_{2}$ plays an important protective role against oxidation in wine, the chemical degradation of this compound during storage may represent a good index of oxidative degradation of the product as a function of the packaging used (Fu et al., 2009; VENTURI et al., 2016a).

Generally, in wine, $\mathrm{SO}_{2}$ can exist in many interconvertible forms, represented by a variety of "free" $\left(\mathrm{FSO}_{2}\right)$ and "bound" $\left(\mathrm{BSO}_{2}\right)$ forms. In this context, the active level of $\mathrm{SO}_{2}$ is influenced by many factors (i.e. $\mathrm{pH}$, concentration of binding compounds, oxygen availability, etc.) also during wine storage. In this study, the concentration of $\mathrm{TSO}_{2}\left(\mathrm{FSO}_{2}+\mathrm{BSO}_{2}\right)$ has been assumed as a measure of oxidative degradation induced by the storage conditions, since in wine the free fraction represents a chemical intermediate among all above mentioned forms of $\mathrm{SO}_{2}$, and its concentration can be affected by several chemical reactions other than oxidation.

As reported in a previous paper (VENTURI et al., 2016a), the time evolution of $\mathrm{TSO}_{2}$ concentration can be described by a first order kinetic equation:

$$
-\mathrm{d}\left[\mathrm{TSO}_{2}\right]_{\mathrm{t}=\mathrm{t}} / \mathrm{dt}=\mathrm{k}_{\mathrm{TSO}_{2}} \cdot\left[\mathrm{TSO}_{2}\right]_{\mathrm{t}=\mathrm{t}}
$$

where $\mathrm{k}_{\mathrm{TSO}_{2}}$ is the kinetic constant related to $\mathrm{TSO}_{2}$ degradation and $\left[\mathrm{TSO}_{2}\right]_{\mathrm{t}=\mathrm{t}}$ is the concentration of total $\mathrm{SO}_{2}$ at the generic reaction time $\mathrm{t}=\mathrm{t}$.

After integration, the following equation can be obtained:

$$
\left[\mathrm{TSO}_{2}\right]_{\mathrm{t}=\mathrm{t}}=\left[\mathrm{TSO}_{2}\right]_{\mathrm{t}=0} \cdot \mathrm{e}^{-\mathrm{krSO}_{2 \mathrm{t}}}
$$

The two functional parameters, $\mathrm{k}$ and $\left[\mathrm{TSO}_{2}\right]_{\mathrm{t}=0}$, were assumed to be valid measures of the effect induced by oxidation during wine storage as a function of adopted packaging and storage temperature. To identify the best values to be assigned to the functional parameters $\left(\mathrm{k}\right.$ and $\left[\mathrm{TSO}_{2}\right]_{\mathrm{t}=0}$ ) involved in equation (5), the statistical program Burenl was utilised (BuzZI FERRARIS \& MANCA, 1996). As shown in Figure 1, the high values assumed by the squares of the correlation coefficients calculated for the linearized form of the kinetic equation in the Taylor series indicate both the suitability of the theoretical approach followed and the reliability of the kinetic equations proposed.

Colour is one of the most important organoleptic characteristics of red wine, affecting the quality evaluation of the product (BIMPILAs et al., 2016). Anthocyanins are the main compounds involved in the colour of young red wine, and the change of colour during aging from red-purple to brick red hues is greatly influenced by the level of oxygen dissolved in the wine during storage (Avizcuri et al., 2016).

The experimental approach proposed above to describe $\mathrm{TSO}_{2}$ time evolution was also followed to describe the time evolution of the concentration of total anthocyanins (TAnt) that may represent a second index of oxidative degradation of the product as a function of the packaging used.

The influence of packaging on the oxidation of red wine appeared evident (Fig. 1, Table 2 ) and, under the working conditions, the differences in degradation rate, as a function of packaging, are statistically significant for both chemical compounds utilized as indexes of wine oxidation. In particular, working at room temperature, the reduction of the concentration of both $\mathrm{TSO}_{2}$ and TAnt was faster when the red wine was stored in multilayer Tetrabriks® (see Table 2: Run 1 vs Run 3). Furthermore, regardless of the packaging material utilized, the 
time evolution of red wine during storage, in terms of both $\mathrm{TSO}_{2}$ and TAnt, appeared delayed as a consequence of the reduction of the storage temperature (see Table 2: Run 3 vs Run 4; Run 1 vs Run 2).

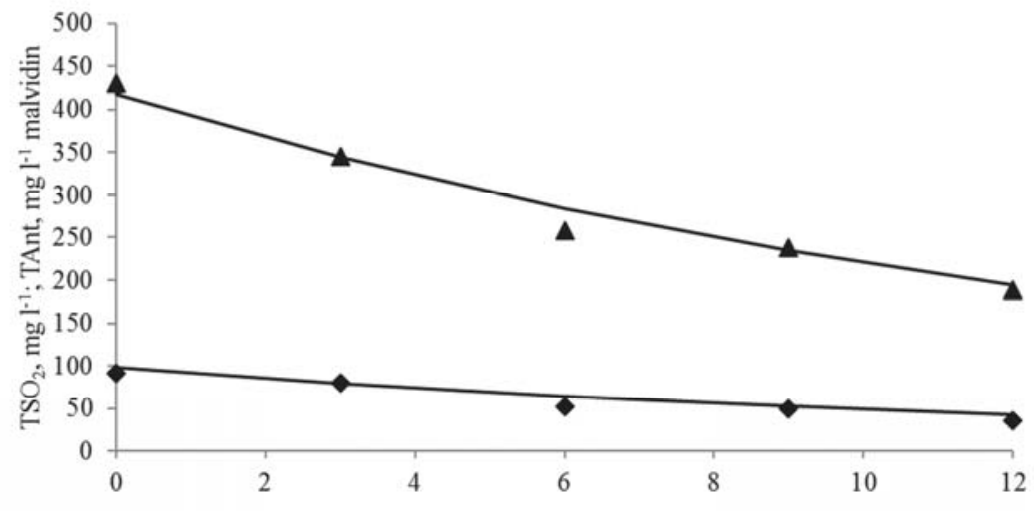

Time from bottling/packaging, months

Fig. 1. Evolution of experimental and calculated points (Run 3) by the kinetic equation introduced, related to $\mathrm{TSO}_{2}$ and TAnt concentration during 12 months of storage. Run 3: Tetrabriks ${ }^{\circledR}, 20^{\circ} \mathrm{C} . \mathbf{\Lambda}$ : TAnt; $: \mathrm{TSO}_{2}$

Table 2. Kinetic parameters describing the time evolution of $\mathrm{TSO}_{2}$ and $\mathrm{TAnt}$ concentration as function of the packaging material and storage conditions

\begin{tabular}{|c|c|c|c|c|}
\hline Run & Storage conditions & $\begin{array}{l}\mathrm{k}_{\mathrm{TSO}_{2}} \pm \mathrm{c} . \mathrm{i} \\
\text { (months } \\
-1 \text { ) }\end{array}$ & $\begin{array}{c}{\left[\mathrm{TSO}_{2}\right]_{\mathrm{t}=0} \pm \text { c.i. }} \\
\left(\mathrm{mg} \mathrm{l}^{-1}\right)\end{array}$ & $\mathrm{r}^{2}$ \\
\hline 1 & Glass $20^{\circ} \mathrm{C}$ & $0.053 \pm 0.0002$ & $106.50 \pm 0.13$ & 0.96 \\
\hline 2 & Glass $4{ }^{\circ} \mathrm{C}$ & $0.045 \pm 0.0006$ & $105.60 \pm 0.38$ & 0.98 \\
\hline 3 & TB $20^{\circ} \mathrm{C}$ & $0.070 \pm 0.0002$ & $98.11 \pm 0.13$ & 0.96 \\
\hline 4 & $\mathrm{~TB} 4{ }^{\circ} \mathrm{C}$ & $0.043 \pm 0.0072$ & $97.39 \pm 0.38$ & 0.63 \\
\hline Run & Storage conditions & $\begin{array}{l}\mathrm{k}_{\text {TAnn }} \pm \mathrm{c} . \mathrm{i} . \\
\left(\text { months }^{-1}\right)\end{array}$ & 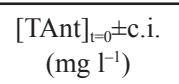 & $\mathrm{r}^{2}$ \\
\hline 1 & Glass $20^{\circ} \mathrm{C}$ & $0.056 \pm 0.0004$ & $459.78 \pm 0.13$ & 0.98 \\
\hline 2 & Glass $4{ }^{\circ} \mathrm{C}$ & $0.020 \pm 0.0001$ & $466.20 \pm 0.37$ & 0.98 \\
\hline 3 & TB $20^{\circ} \mathrm{C}$ & $0.064 \pm 0.0005$ & $417.99 \pm 0.13$ & 0.98 \\
\hline 4 & TB $4{ }^{\circ} \mathrm{C}$ & $0.022 \pm 0.0001$ & $423.77 \pm 0.38$ & 0.94 \\
\hline
\end{tabular}

\subsection{Sensorial evolution of stored wine}

After 12 months of storage (Fig. 2), the wine maintained at $4{ }^{\circ} \mathrm{C}$ in glass bottles (Run 2) showed the best sensorial profile, while the fastest deterioration of wine was observed when it was stored in Tetrabriks ${ }^{\circledR}$ at room temperature (Run 3). 


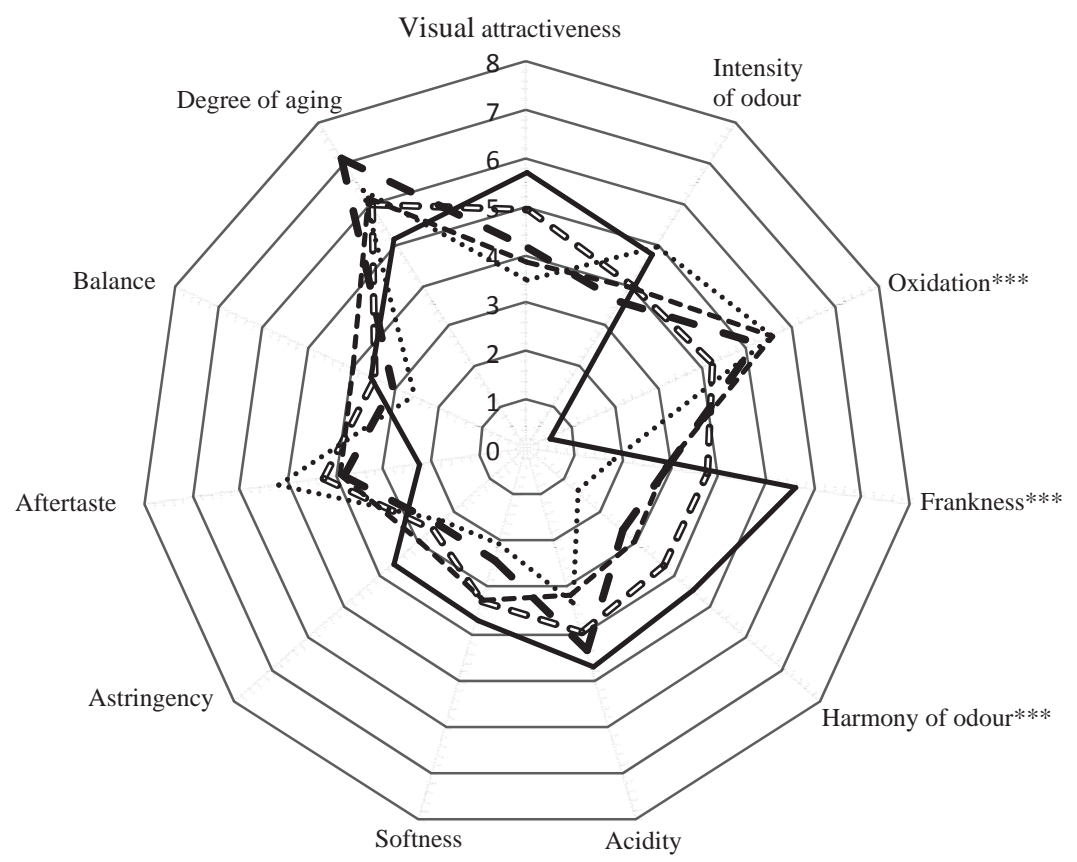

Fig. 2. Sensorial profile of wine as a function of packaging material and storage conditions ( $\mathrm{t}=12 \mathrm{month}$ from bottling/packaging). ***: $\mathrm{P}<0.001 ; * *: \mathrm{P}<0.01 ; *$ * $\mathrm{P}<0.05$

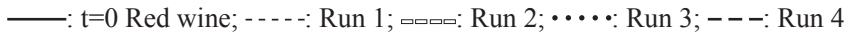

Furthermore, to verify whether and how the sensory properties of wine changed over time, the Two-way ANOVA, with Product and Panelist as main effects, was performed on the experimental data related to the sensory attributes at different storage times. The results of the ANOVA applied to the main attributes utilized to describe view, smell, and taste are reported (Figs 3A, 3B). Among all descriptors ranked by the panel components, only parameters that showed statistically significant differences under one or more storage conditions are reported and discussed.

In particular, according to storage time, it was possible to observe that the number of attributes useful in discriminating wines stored in different packaging as well as the significance level of the observed differences increased.

Furthermore, similarly to the chemical evolution observed, it was possible to determine that the sensorial evolution of red wine during bottle aging was significantly delayed at the lowest temperature, regardless of the packaging material utilized, while at room temperature, glass allowed better preservation of the quality of the stored wine. 
A

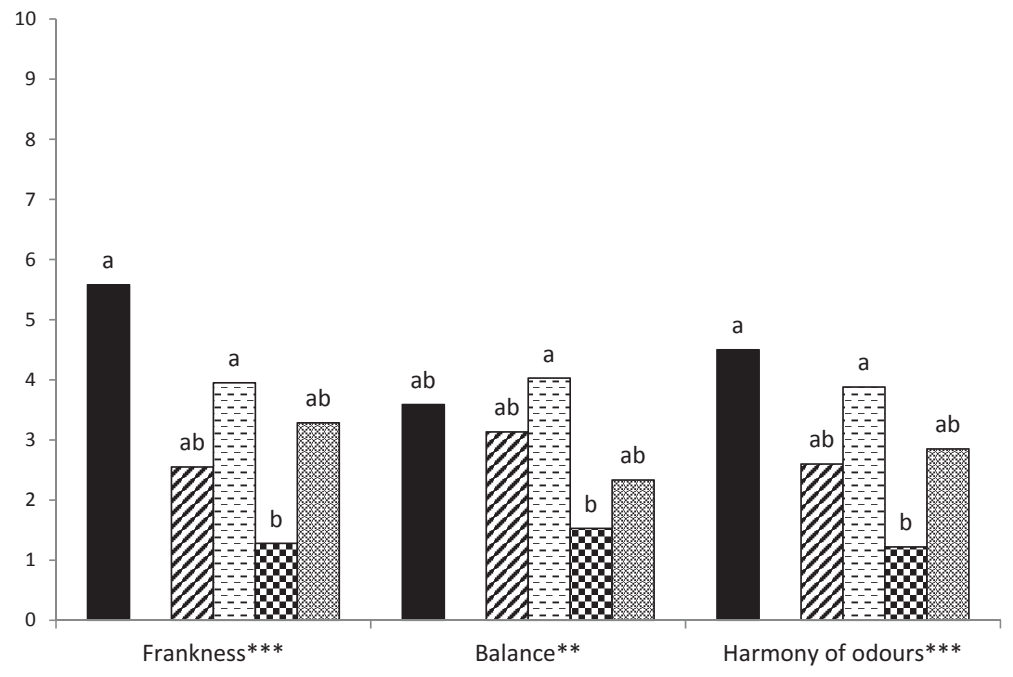

B

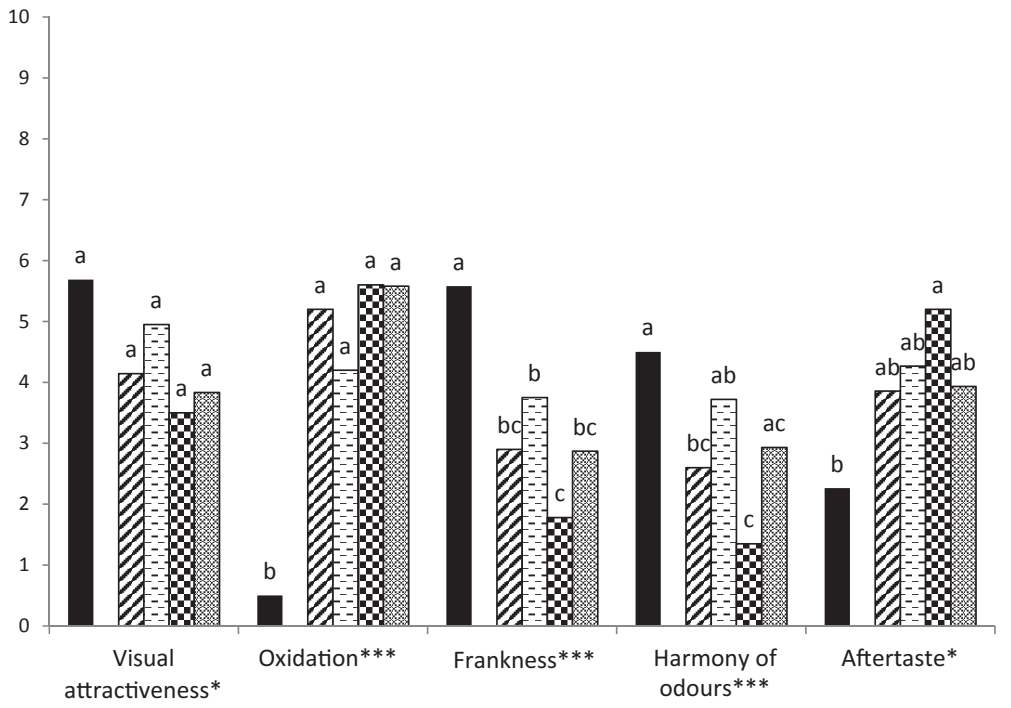

Fig. 3. Main sensorial descriptors ranked by panel components during storage time (Figure $3 \mathrm{~A}, \mathrm{t}=6$ months from bottling/packaging; Figure 3B, t=12 months from bottling/packaging). At the same storage time, parameters not sharing the same letter have a significantly different mean value. ***: $\mathrm{P}<0.001 ; * *: \mathrm{P}<0.01 ; *: \mathrm{P}<0.05$

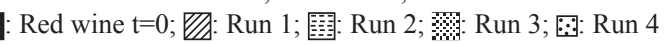

\subsection{Matrix of correlation}

In order to evidence whether the rate of $\mathrm{TSO}_{2}$ degradation, as well as that of TAnt, could represent a chemical index of the evolution of the red wine during storage, the two kinetic constants, $\mathrm{k}_{\mathrm{TSO}_{2}}$ and $\mathrm{k}_{\mathrm{TAnt}}($ Table 2 ), were correlated for all storage conditions with the sensory attributes reported in Figure 3B. The correlation coefficients are presented in Table 3. 
Table 3. Correlation matrix relating the kinetic constants describing $\mathrm{TSO}_{2}$ and $\mathrm{TAnt}$ degradation to each other and to wine sensory attributes (storage time $=12$ months)

\begin{tabular}{lcc}
\hline Parameter & $\mathrm{k}_{\mathrm{TSO}_{2}}$ & $\mathrm{k}_{\text {TAnt }}$ \\
\hline $\mathrm{k}_{\mathrm{TSO}_{2}}$ & 1.00 & $0.89^{*}$ \\
Visual attractiveness & $<0.7$ & $<0.7$ \\
Aftertaste & $0.85^{*}$ & $<0.7$ \\
Frankness & $-0.86^{*}$ & $-0.78^{*}$ \\
Harmony of odours & $-0.92^{*}$ & $-0.87^{*}$ \\
Oxidation & $<0.7$ & $<0.7$ \\
\hline
\end{tabular}

*: Correlation coefficient that indicates a strong correlation $(\geq 0.7)$

Thus, it has been proved that both $\mathrm{TSO}_{2}$ and TAnt degradation kinetic constants $\left(\mathrm{k}_{\mathrm{TSO}_{2}}\right.$ and $\mathrm{k}_{\mathrm{TAnt}}$ ) are strongly inversely correlated to positive sensorial attributes such as "Harmony of odours" and "Frankness", while negative attribute "Aftertaste" was strongly directly correlated with $\mathrm{k}_{\mathrm{TSO}_{2}}$.

\section{Conclusions}

On the basis of the experimental data, a new "integrated approach", deriving from the merging of chemical, kinetic, and sensorial data, can be introduced to identify the best packaging and storage conditions to maintain the quality of red wine during storage. In this context, $\mathrm{k}_{\mathrm{TSO}_{2}}$ as well as $\mathrm{k}_{\mathrm{TAnt}}$ represent two useful indexes to describe the chemical evolution of red wine in combination with the main sensorial attributes generally associated with oxidative evolution of this kind of product.

\section{References}

Amerine, M.A. \& Ough C.S. (1988): Wine and must analysis. John Wiley and Sons, New York. 400 pages.

Avizcuri, J-M., SÁenz-Navajas, M-P., Echávarri, J-F., Ferreira, V. \& Fernández-Zurbano, P. (2016): Evaluation of the impact of initial red wine composition on changes in colour and anthocyanin content during bottle storage. Food Chem., 213, 123-134.

Bimpilas, A., Panagopoulou, M., Tsimogiannis, D. \& Oreopoulou, V. (2016): Anthocyanin copigmentation and colour of wine: the effect of naturally obtained hydroxycinnamic acids as cofactors. Food Chem., 197, 39-46.

Buzzi Ferraris, G. \& Manca, D. (1996): BURENL. Politecnico, Dipartimento di Ingegneria Chimica 'G. Natta', Milan.

Cleary, J. (2013): Life cycle assessments of wine and spirits packaging at the product and the municipal scale: a Toronto, Canada case study. J. Clean. Prod., 44, 143-151.

Dombre, C., Rigou, P., Wirth, J. \& Chalier, P. (2015): Aromatic evolution of wine packed in virgin and recycled PET bottles. Food Chem., 176, 376-387.

Fu, Y., Lim, L.T. \& McNicholas, P.D. (2009): Changes on enological parameters of white wine packaged in bag-inbox during secondary shelf life. J. Food Sci., 74, 608-618.

Ghidossi, R., Poupot, C., Thiвon, C. \& Mietton-Peuchot, Mme. (2012): The influence of packaging on wine conservation. Food Control, 23, 302-311.

Kwiatkowski, M.J., Skouroumounis, G.K., Lattey, K.A. \& Waters, E.J. (2007): The impact of closures, including screw cap with three different headspace volumes, on the composition, colour and sensory properties of a Cabernet Sauvignon wine during two years' storage. Aust. J. Grape Wine R., 13(2), 81-94. 
Leighton, C.S., Schönfeldt, H.C. \& Kruger, R. (2010): Quantitative descriptive sensory analysis of five different cultivars of sweet potato to determine sensory and textural profiles. J. Sens. Stud., 25, 2-18.

Mentana, A., Pati, S., La Notte, E. \& Del Nobile, M.A. (2009): Chemical changes in Apulia table wines as affected by plastic packages. LWT - Food Sci. Technol., 42, 1360-1366.

OIV (2014): Compendium of international methods of wine and must analysis, Vol. 1, 2. OIV, Paris.

Pérez Elortondo, F.J., Ojeda, M., Albisu, M., Salmerón, J., Etayo, I. \& Molina, M. (2007): Food quality certification: An approach for the development of accredited sensory evaluation methods. Food Qual. Prefer., $18,425-439$.

Revi, M., Badeka, A., Kontakos, S. \& Kontominas M.G. (2014): Effect of packaging material on enological parameters and volatile compounds of dry white wine. Food Chem., 152, 331-339.

RoBertson, G.L. (2012): Food packaging: principles and practice. CRC press, Boca Raton, Fl., USA, 733 pages.

Vanderroost, M., Ragaert, P., Devlieghere, F. \& Meulenaer, B. (2014): Intelligent food packaging: The next generation. Trends Food Sci. Tech., 39, 47-62.

Van Ooijen, I., Fransen, M.L., Verlegh, P.W.J. \& Smit, E.G. (2016): A typical food packaging affects the persuasive impact of product claims. Food Qual. Prefer., 48, 33-40.

Venturi, F., Zinnai, A., Fantoni, G., Gabelloni, D. \& Razionale, A.V. (2013): Glass and wine: The indissoluble marriage. Proceedings of the International Conference on Engineering Design, ICED, 7 DS75-07, pp. 497506.

Venturi, F., Andrich, G., Sanmartin, C., Scalabrelli, G., Ferroni, G. \& Zinnai, A. (2014): The expression of a fullbodied red wine as a function of the characteristics of the glass utilized for the tasting. CYTA - J. Food, 12(3), 291-297.

Venturi, F., Andrich, G., Sanmartin, C., Taglieri, I., Serni, E. \& Zinnai, A. (2015): Winemaking of Sangiovese grapes with and without the addition of different oenological tannins in order to increase the colour intensity of chianti wine. Agrochimica, 59, 261-271.

Venturi, F., Sanmartin, C., Taglieri, I., Xiaogou, Y., Andrich, G. \& Zinnai, A. (2016a): The influence of packaging on the sensorial evolution of white wine as a function of the operating conditions adopted during storage. Agrochimica, 60, 150-160.

Venturi, F., Andrich, G., Sanmartin, C., Taglieri, I., Scalabrelli, G., Ferroni, G. \& Zinnai, A. (2016b): Glass and wine: A good example of the deep relationship between drinkware and beverage. J. Wine Res., 27, $153-171$.

Wani, A.A., Singh, P. \& Langowski, H-C. (2014): Food technologies: Packaging. Encyclopedia of food safety. Food, Materials, Technologies and Risks, 3, 211-218.

Zinnai, A., Venturi, F. \& ANDrich, G. (2011a): Time evolution of phenols extractions from Sangiovese grapes with and without the addition of solid carbon dioxide. Agrochimica, 55(4), 193-202.

Zinnai, A., Venturi, F., Quartacci, M.F. \& Andrich, G. (2011b): A mathematical model to describe malolactic fermentation. Ital. J. Food Sci., 23(1), 80-89.

Zoecklein, B.W., Fugelsang, K.C., Gump, B.H. \& Nuri F.S. (1999): Wine analysis and production. Kluwer Academic/Plenum Publishers, New York, pp. 19-20. 